\title{
Exacerbation of Oxazolone Colitis by Infection with the Helminth Hymenolepis diminuta
}

\author{
Involvement of IL-5 and Eosinophils
}

\begin{abstract}
Arthur Wang, Maria Fernando, Gabriella Leung, Van Phan, David Smyth, and Derek M. McKay

From the Gastrointestinal Research Group, Department of Physiology and Pharmacology; the Calvin, Phoebe, and Joan Snyder Institute of Infection, Immunity and Inflammation, University of Calgary, Calgary, Alberta, Canada
\end{abstract}

Substantial data show that infection with helminth parasites ameliorates colitis; however, oxazolone-induced colitis is exaggerated in mice infected with the tapeworm, Hymenolepis diminuta. We tested the hypothesis that the IL-5 response to helminth infection enhances the severity of oxazolone-induced colitis. Mice were infected with $H$. diminuta and 8 days later were treated with oxazolone \pm anti-IL-5 antibodies. Colitis was assessed 72 hours postoxazolone treatment by disease activity scores, myeloperoxidase activity, and histopathology. Other mice received injections of a replication-deficient adenovirus that carried the IL-5 (Ad.IL-5) gene or a control adenovirus (Ad.delete) \pm oxazolone. The effect of $H$. diminuta+oxazolone in CCL11/CCL22 (eotaxin-1 and 2) knockout (KO) mice was determined. Helminth infection and Ad.IL-5 treatment increased IL-5 and eosinophil numbers. In vivo neutralization of IL-5 significantly reduced the severity of colitis in $\boldsymbol{H}$. diminuta + oxazolone-treated mice, and $\boldsymbol{H}$. diminuta did not exaggerate oxazolone-induced colitis in CCL11/CCL22 KO mice. Mice receiving Ad.IL-5 only had no colitis, while oxazolone-induced colitis was more severe in animals cotreated with Ad.IL-5 (Ad.delete + oxazolone was not significantly different from oxazolone only). Thus, while there is much to be gleaned about antiinflammatory mechanisms from rodent-helminth model systems, these data illustrate the caveat that infection with helminth parasites as a therapy could be contraindicated in patients with eosinophilia or elevated IL-5 unless coupled to appropriate measures to block IL-5 and/or eosinophil activity. (Am J Pathol 2010, 177:2850-2859; DOI: 10.2353/ajpath.2010.100537)

The potential of infection with parasitic helminths to reduce the severity of concomitant disease has been the focus of a cadre of investigators, who, using a variety of model systems, have produced substantial proof-of-concept data that infection with nematode, trematode, or cestode parasites reduces disease in animal models of inflammatory and autoimmune disease. ${ }^{1}$ Collectively, these studies have shown that as a consequence of the host response to infection with helminth parasites, there is mobilization of transforming growth factor (TGF)- $\beta$, interleukin (IL)-10, Foxp3 ${ }^{+}$regulatory $T$ cells, alternatively activated macrophages, and inhibition of IL-17- and interferon (IFN)- $\gamma$-driven events: one, or a combination, of these events could block the development of autoimmune and inflammatory disorders. ${ }^{2-7}$ These findings have been complemented by intriguing data suggesting that infection with viable parasitic nematodes could be a treatment for patients with inflammatory bowel disease $(\mathrm{IBD})^{8}$ or asthma, ${ }^{9}$ whose condition is not managed by conventional therapies.

We have contributed to the concept of 'helminth therapy,' noting that while specific helminths may be identified that can be used as a treatment, the information gleaned from analyses of helminth-rodent model systems could also be the basis for the development of novel therapeutic approaches. ${ }^{10}$ However, parasitism comes at a cost to the host, and many species take a huge toll on

Supported by an operating grant from the Crohn's and Colitis Foundation of Canada (D.M.M.). D.M.M. is a Canada Research Chair (Tier 1) and an Alberta Heritage for Medical Research (AHFMR) Scientist.

Accepted for publication August 13, 2010.

Authors have no financial or other conflicts to declare.

Address reprint requests to Derek M. McKay, Ph.D., Professor, Department of Physiology and Pharmacology, 1717 HSC, University of Calgary, 3330 Hospital Drive NW, Calgary, Alberta, T2N 4N1, Canada. E-mail: dmckay@ucalgary.ca. 
human health and well-being. ${ }^{11}$ This coupled to the spectre of iatrogenic disease ${ }^{12}$ means that one must be vigilant of the potential for infection with helminth parasites to exaggerate disease, and to provoke deleterious sideeffects. In this context, we showed that in contrast to the dinitrobenzene sulfonic acid (DNBS) model of colitis, ${ }^{3}$ mice infected with the rat tapeworm Hymenolepis diminuta developed significantly more severe colonic inflammation when challenged intrarectally (ir.) with oxazolone. ${ }^{13}$ Grossly, DNBS and oxazolone-induced colitis in mice look similar but they are different in etiology and histopathology: one of the more notable differences being an increase in eosinophils in the colon of oxazolone-treated mice. $^{14,15}$

Because a stereotypic human and murine response to infection with helminth parasites is eosinophilia, we hypothesized that the enhancement of oxazolone-induced colitis by infection with $H$. diminuta could be due to IL-5 and consequently eosinophils. To test this postulate, i) $H$. diminuta + oxazolone-treated mice were administered anti-IL-5 antibodies, and ii) mice were treated with adenovirus carrying the murine IL-5 gene \pm oxazolone. In vivo neutralization of IL-5 blocked the enhanced colitis that develops in $\mathrm{H}$. diminuta+oxazolone treated mice and in accordance with these data, overexpression of IL-5 resulted in a more severe disease in oxazolone cotreated mice. Many variables are at play in animal models, and while none fully recapitulate human disease, we present these data as a caveat that individuals with eosinophilia may not be good candidates for 'helminth therapy,' unless this is coupled with other therapeutics to block the effects of IL-5 and/or other eosinophil-derived molecules.

\section{Materials and Methods}

\section{Mice and Induction of Colitis}

Colitis was induced in anesthetized male BALB/c mice (7-9 weeks old; Charles River Animal suppliers, Quebec, Canada), BALB/c mice engineered to lack CCL11/CCL22 (kindly provided by Dr. M. Rothenberg, University of Cincinnati, Ohio ${ }^{16}$ ) and BALB/c mice lacking the $\alpha$ chain of the IL-4 receptor (IL-4R $\alpha$ : kindly provided by Dr. F. Brombacher, University of Cape Town, South Africa) via the intrarectal (ir.) delivery of 3 or $4 \mathrm{mg}$ of oxazolone in $100 \mu \mathrm{l}$ of 1:1 PBS:ethanol using a 3-cm lubricated polyethylene catheter. ${ }^{13}$ Time-matched vehicle-only treated mice served as controls. Mice were humanely sacrificed 72 hours postoxazolone treatment. Some studies using oxazolone use a sensitization and ir. rechallenge protocol. ${ }^{14}$ We opted to use a single ir. delivery in accordance with our earlier study and for comparisons with the DNBS model of colitis. ${ }^{3}$ Experiments conformed to the Canadian guidelines for animal welfare.

\section{Adenoviral Administration}

The adenovirus used was engineered to lack the E1 region and thus was replication-deficient and had the murine IL-5 gene inserted into its genome (Ad.IL-5). ${ }^{17}$
Replication-deficient adenovirus with no additional gene insertions (ie, Ad. delete) were used as a control. ${ }^{17}$ Under light anesthesia, mice received an intraperitoneal injection of either Ad.IL-5 or Ad.delete $\left[10^{8}\right.$ plaque forming units (pfu) of adenovirus/100 $\mu$ l sterile PBS: adenovirus kindly provided by Dr. Z. Xing, McMaster University, Hamilton, ON, Canada] and 48 hours later were randomized into those receiving PBS or oxazolone.

\section{Infection with $\mathrm{H}$. diminuta and Treatment with in Vivo IL-5 Antibody}

Mice under manual restraint received an oral gavage of $100 \mu \mathrm{l}$ of sterile PBS containing five viable cysticercoids of $H$. diminuta and were challenged with oxazolone 8 days later. ${ }^{13}$ Other mice were administered a total of $200 \mu \mathrm{g}$ of anti-IL-5 (TRK5, a rat IgG ${ }_{1}$ : Cat\# MM550C Pierce Endogen, Rockford, IL) delivered i.p. to lightly anesthetized mice $5(50 \mu \mathrm{g} \mathrm{AB}), 7(100 \mu \mathrm{g} \mathrm{AB})$ and $9(50 \mu \mathrm{g} \mathrm{AB})$ days postinfection (with oxazolone treatment at 8 days postinfection). ${ }^{3}$ Time-matched controls consisted of oxazolone + anti-IL-5 treatment and mice treated with an irrelevant rat $\lg G_{1}$ (Biolegend, San Diego, CA).

\section{Assessment of Colitis}

\section{Macroscopic Assessment}

After oxazolone treatment the mice were monitored daily for signs of disease, including diarrhea (ie, wet or faecal-stained anus), weight loss, and behavioral changes (eg, lethargy, ruffled fur). At sacrifice, the entire colon was excised, weighed, and examined for signs of damage/ulceration. A disease activity score (DAS) was determined using a 5 point-scale: $>10 \%$ drop in body weight ( 0 or 1 ); soft/loose stool, empty colon, wet anus ( 0 or 1); evidence of active bleeding or occult blood (0 or 1$)$; presence of macroscopic ulcers (0 or 1); a maximum score of 5 was given if any animal had to be humanely sacrificed because of reaching a pre-determined endpoint in disease severity. ${ }^{13}$ Because colitis results in shortening of the colon, colons were divided based on percentage of total length: the distal $10 \%$ was discarded, the next 20\% was frozen in liquid nitrogen for use in the myeloperoxidase (MPO; an indicator of granulocyte infiltrate) and eosinophil peroxidase (EPO) assay, and the next $20 \%$ (ie, the most proximal segment) was fixed in formalin for histological analysis.

\section{Myeloperoxidase (MPO) and Eosinophil Peroxidase (EPO) Determinations}

MPO (a marker of acute inflammation often associated with neutrophil infiltration) and EPO (a specific eosinophil marker) activities were determined in tissue extracts and the human acute promyelocytic leukemia cell line, HL-60 (clone 15) (ATCC), differentiated into eosinophils by culture for 7 days with $0.5 \mathrm{mmol} / \mathrm{L}$ butyric acid (Sigma Chemical Co.) and $5 \mathrm{ng} / \mathrm{ml}$ granulocyte macrophage col- 
ony stimulating factor (GM-CSF: R \& D systems) ${ }^{18}$ via a colorimetric kinetic assay in which $\mathrm{H}_{2} \mathrm{O}_{2}$ catabolism is measured. One unit of MPO activity in the samples is the amount of enzyme required to degrade $1 \mu \mathrm{mol} / \mathrm{L} \mathrm{H}_{2} \mathrm{O}_{2} /$ minute. The assay was repeated in the presence of 50 mmol/L 3-amino-1,2,4-triazole (AMT: Sigma Chemical Co.) to inhibit EPO, whose activity was calculated by subtracting the MPO+AMT value from the MPO value only. ${ }^{13}$

\section{Histological Assessment}

Segments of the colon were immersion-fixed in 10\% buffered formalin (72 hours), dehydrated in graded alcohols, cleared in xylene, and embedded in paraffin wax. Sections ( $3 \mu \mathrm{m})$ were collected on coded slides, stained with hematoxylin and eosin and a histological damage score calculated on 12-point scale as previously described. ${ }^{13}$ Eosinophils were counted in 5 random high power ( $\times 40$ objective) fields (HPF) of view.

\section{Cytokine Production}

Serum was obtained from murine blood samples 24 hours after Ad.IL-5 injection and in additional studies 72 hours after oxazolone and stored at $-80^{\circ} \mathrm{C}$. Interleukin-5 levels were determined by ELISA. Spleen cells, mesenteric lymph node (MLN) cells, or colonic lamina propria lymphocytes $(\mathrm{LPLS})^{19}$ were isolated and $5 \times 10^{6}$ cells stimulated with concanavalin A (ConA: $2 \mu \mathrm{g} / \mathrm{ml}$ ) for 48 hours, cell-free supernatants collected, and levels of IL-4, IL-5, and IL-10 measured. All ELISAs were performed in duplicate using antibody pairs from R\&D Systems (Minneapolis, MN) and each assay had a limit of detection of $8 \mathrm{pg} / \mathrm{ml}$.

\section{Eosinophil Counts}

Blood smears or cytospin preparations of bone-marrow cells retrieved from murine femurs were stained using the Hema3 differential staining kit (Fisher Scientific, Kalamazoo, MI) and mononuclear cells, neutrophils, and eosinophils counted.

\section{Epithelial Barrier Function}

One million cells of the human colon-derived T84 cell line were seeded onto porous filter supports and cultured as described ${ }^{20}$ (human cell lines were used for these studies because of the lack of a mouse colon-derived epithelial cell line suitable for use in barrier studies). On reaching confluence (defined as transepithelial resistance (TER) $\geq 750 \Omega / \mathrm{cm}^{2}$ ), monolayers were cultured with $1 \times$ $10^{5} \mathrm{HL}-60$ eosinophils (in the basal compartment of the culture well) \pm LPS (Escherichia coli, $100 \mathrm{ng} / \mathrm{ml}$; Sigma Chemical Co.) and epithelial barrier function assessed by measurements of TER and the lumen to basal flux of horseradish peroxidase (HRP) after a 48-hour period: i) TER was measured using a voltmeter and matched elec- trodes (Millipore) at the beginning and end of the experiments and is presented as percentage of pretreatment values $^{21}$; ii) HRP (20 ng type Vl; Sigma Chemical Co.) was added to the apical chamber $(1 \mathrm{ml}$ vol.) of the well and three $10 \mu \mathrm{l}$ samples of culture medium were collected from the basolateral chamber, diluted (1:10) in $0.5 \%$ HTAB buffer and enzymatic activity determined by spectrophotometric measurement $\left(\mathrm{OD}_{450} \mathrm{~nm}\right)$ of $3,3^{\prime}, 5,5^{\prime}$ tetramethylbenzidine (TMB) oxidation after the reaction was terminated with $2 \mathrm{~N} \mathrm{H}_{2} \mathrm{SO}_{4}$, and HRP determined against a concentration curve.

\section{Statistical Analysis}

All data are presented as the mean \pm SEM, where $n$ is the total number of mice. Statistical comparisons were performed via one-way analysis of variance, followed by post hoc pair-wise comparisons of the groups with either Student's $t$-test or Tukey's test, as appropriate and $P<0.05$ set as a statistically significant difference.

\section{Results}

\section{Use of an Anti-IL-5 Antibody Reduces the Exaggeration of Oxazolone-Induced Colitis in Mice Infected with $\mathrm{H}$. diminuta}

Direct ir. instillation of oxazolone resulted in an acute and self-resolving colitis: disease severity peaking 1-3 days posttreatment, with significant spontaneous healing by day 7 posttreatment $\left(n=6-7\right.$ mice; data not shown). ${ }^{13}$ Normal BALB/C animals completely expel $H$. diminuta, whereas intestinal washings from IL-4R $\alpha \mathrm{KO}$ mice revealed that these animals failed to spontaneously reject the helminth. Eleven days after infection $12 \mathrm{H}$. diminuta (length range $=8-12 \mathrm{~cm}$; total biomass $=269.5 \mathrm{mg}$ ) were retrieved from the small intestine of $3 \mathrm{IL}-4 \mathrm{R} \alpha \mathrm{KO}$ mice (nb. each mouse given 5 cysticercoids), whereas no worms were obtained from time-matched identically infected wild-type BALB/c mice. Oxazolone-induced colitis in IL-4R $\alpha \mathrm{KO}$ mice was less severe than that observed in wild-type BALB/c mice (DAS $=3.8 \pm 0.5$ and $1.8 \pm 0.5^{\star}$ for wild-type and IL-4R $\alpha \mathrm{KO}$ mice respectively ( $n=7$ mice, ${ }^{\star} P<0.05$ ), affirming a role for IL-4R $\alpha$ signaling in the disease process and this is consistent with other studies using this model system. ${ }^{14}$

Successful infection with $H$. diminuta in BALB/c mice was confirmed by elevated IL-4 production from ConAstimulated spleen cells: $H$. diminuta+oxazolone $=368 \pm$ $144^{*}, H$. diminuta+oxazolone+anti-IL-5 $=898 \pm 302^{*}$, control $=106 \pm 19 \mathrm{pg} / \mathrm{ml}\left(n=4 ;{ }^{*}, P<0.05\right.$ compared to control). Furthermore, IL-5 production by conA-stimulated spleen cells and LPLs was significantly increased in cells from $H$. diminuta-infected mice \pm oxazolone treatment (Figure 1, A and B), and this was paralleled by increased eosinophil production by the bone-marrow (Figure 1C), and eosinophil numbers in the blood (Figure 1D) and colon (Figure 1, E and F). Analysis of circulating and colonic eosinophils revealed no significant differ- 
A

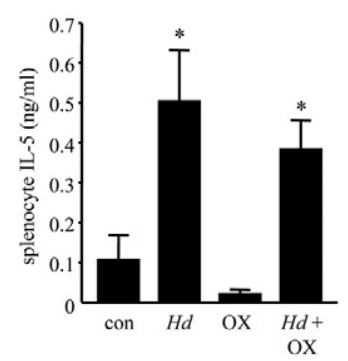

$\mathrm{C}$

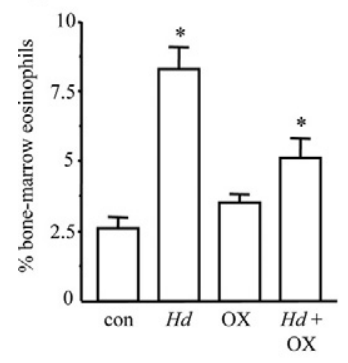

$\mathrm{E}$

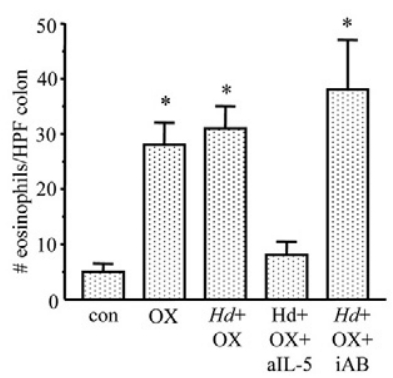

B

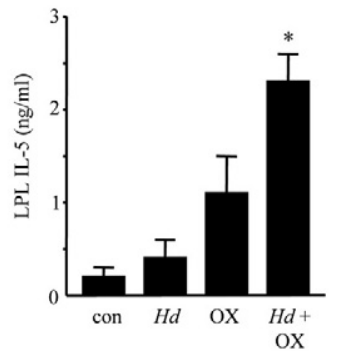

$\mathrm{D}$

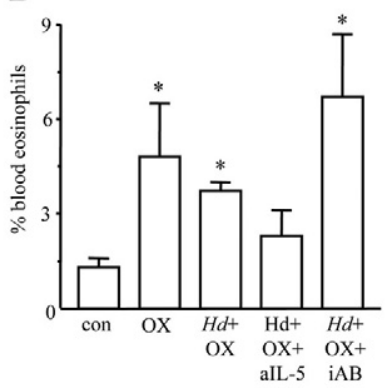

$\mathrm{F}$

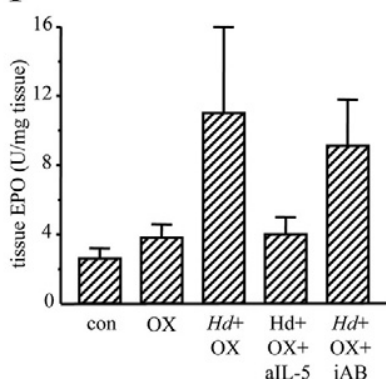

Figure 1. Bar graphs showing increased IL-5 production by ConA ( $2 \mu \mathrm{g}$ ) ml)-stimulated spleen cells and lamina propria lymphocytes (LPLs) in $H$ $\operatorname{diminuta}(H d)$-infected mice [A (representative of three experiments) and $\mathbf{B}$; $n=3$ ). Panels $\mathbf{C}-\mathbf{F}$ illustrate numbers of bone marrow eosinophils, circulating eosinophils, colonic eosinophils, and colonic eosinophil peroxidase (EPO) activity in control (con), oxazolone (OX; $3 \mathrm{mg}$ ir, 72 hours)-treated mice, and $\mathrm{OX}+\mathrm{Hd}$ mice (infected 8 days before $\mathrm{OX}$ ) \pm treatment with anti-IL- $5 \mathrm{AB}$ or an isotype-matched irrelevant $\mathrm{AB}$ (iAB) (mean $\pm \mathrm{SEM} ; n=$ 4 in $\mathbf{B}$ and $\mathbf{D}$ and $6-8$ in $\mathbf{E}$ and $\mathbf{F}$; both antibodies delivered ip. in three doses for a total of $200 \mu \mathrm{g} ;{ }^{*} P<0.05$ compared to control).

ences between naïve mice and those treated with oxazolone $+H$. diminuta +anti-IL-5 AB (Figure 1, D and E).

Consistent with earlier findings, oxazolone-induced colitis was characterized by loss of body weight (Figure 2A), shortening of the colon (Figure 2B), increased disease activity scores (Figure $2 \mathrm{C}$ ), and significant histopathology (Figure 3, A and B). Administration of anti-IL-5 AB did not affect the outcome of oxazolone-induced colitis $(n=4$; Figure 2), suggesting that while eosinophils are recruited to the colon ${ }^{14}$ their overall contribution to oxazoloneinduced colitis is small and masked within the natural variation between mice in their response to oxazolone. Oxazolone-induced colitis was more severe in mice previously infected with $H$. diminuta (Figures 2 and 3$)^{13}$; however, animals that also received anti-IL-5 AB had less colitis than $H$. diminuta +oxazolone treated mice and were similar in phenotype to naïve mice. Mice infected with $H$. diminuta and treated with oxazolone and irrelevant $\lg _{1}$ had severe colitis (Figures 2 and 3 ) that was not statisti-

A

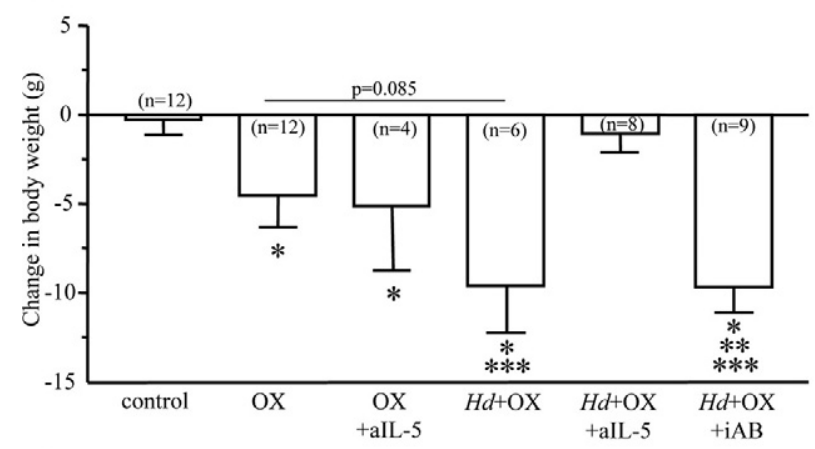

$\mathrm{B}$

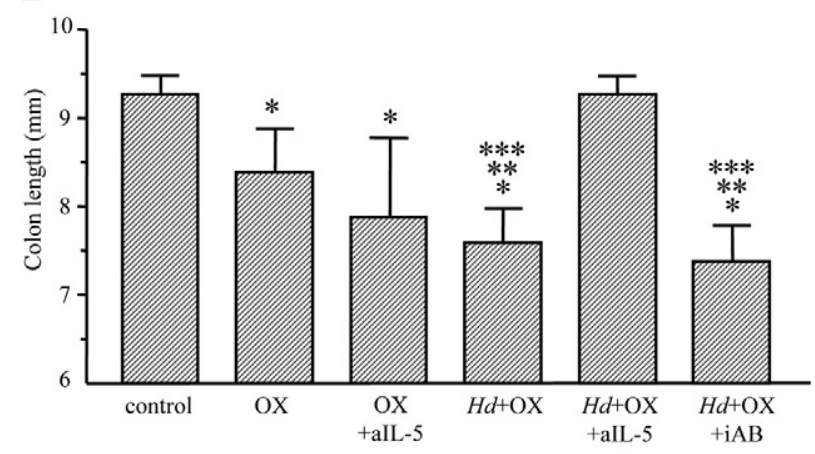

C

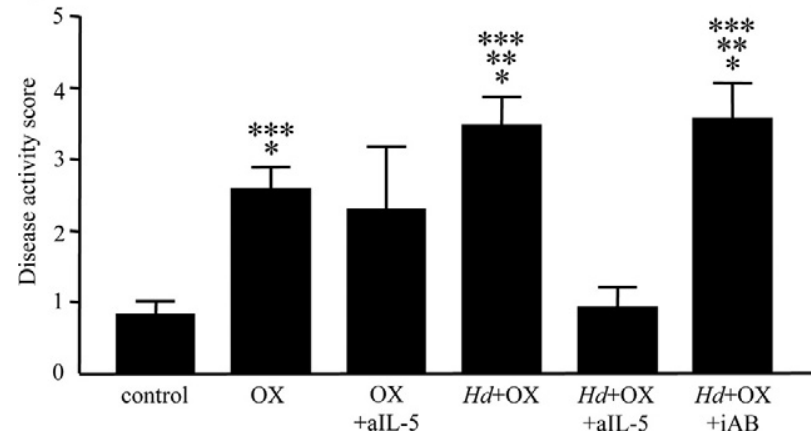

Figure 2. Bar graphs showing reduced colitic disease in mice treated with $H$. diminuta ( $\mathrm{Hd}$; five cysticercoids 8 days before oxazolone)+oxazolone ( 3 mg, ir.) +anti-IL-5 antibody (total $200 \mu \mathrm{g}$ ), as assessed by change in body weight $(\mathbf{A})$, colon length $(\mathbf{B})$, and disease activity scores $(\mathbf{C})$ [mean \pm SEM; $n$ values are shown in parentheses in $\mathbf{A}$ and are from 1 to 3 experiments; assessment conducted 72 hours after oxazolone (OX): ${ }^{*} P<0.05$ compared to control, ${ }^{* *} P<0.05$ compared to oxazolone, and ${ }^{* * * *} P<0.05$ compared to $H$. $d+$ oxazolone + anti-IL-5 $\mathrm{AB}$; iAB, irrelevant antibody $\left.\left(\operatorname{IgG}_{1}\right)\right]$.

cally different from that in $\mathrm{H}$. diminuta+oxazolone-treated mice. These data support an IL-5-eosinophil axis in the exaggeration of oxazolone-induced colitis in $\mathrm{H}$. diminutainfected mice.

\section{Oxazolone-Induced Colitis in CCL11/CCL22 (Eotaxin 1/2) KO Mice Is Not Exaggerated by Infection with $\mathrm{H}$. diminuta}

CCL11/CCL22 KO mice developed colitis in response to topical application of oxazolone that was similar to that observed in wild-type BALB/c mice (Figure 4, A-C). This is consistent with in vivo neutralization of IL-5 having no effect on the outcome of ozaxolone-induced colitis in 
A

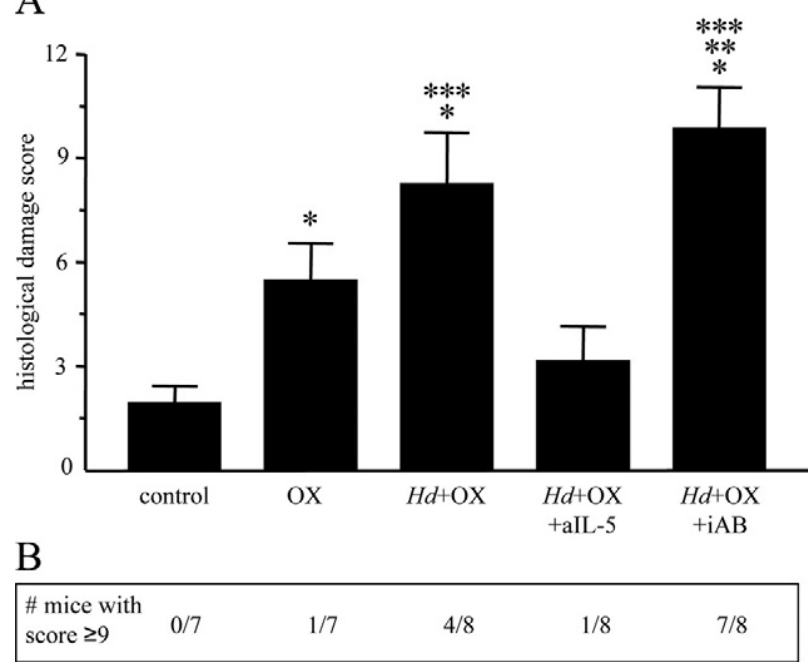

Figure 3. A: histology damage scores in oxazolone $(\mathrm{OX}) \pm H$. diminuta \pm anti-IL-5 antibody-treated mice [mean \pm SEM; $n=7-8$ mice from two experiments; assessment conducted 72 hours after oxazolone (OX); ${ }^{*} P<$ 0.05 compared to control, ${ }^{* *} P<0.05$ compared to oxazolone, and ${ }^{\dagger} P<0.05$ compared to and $H . d+$ oxazolone +anti-IL-5 AB, respectively; iAB, irrelevant antibody $\left(\operatorname{IgG} G_{1}\right)$ ]. B: depicts the number of mice/group with the most severe histological damage as assessed by histological damage scores greater than or equal to 9 .

normal mice (Figure 2, $\mathrm{A}-\mathrm{C}$ ). In contrast to normal $\mathrm{BALB} / \mathrm{c}$ mice, infection with $\mathrm{H}$. diminuta did not exaggerate oxazolone-induced colitis in CCL11/CCL22 KO as gauged by all parameters of disease: disease activity scores, representative histological images and histological damage scores are shown in Figure 4. Indeed, prior infection with $\mathrm{H}$. diminuta led to a degree of protection against oxazolone-induced colitis (Figure 4). Enumeration of eosinophils in histological sections of colons from control $(n=7)$, oxazolone $(n=6)$, and $H$. diminuta+ ozaxolone $(n=6)$-treated CCL11/CCL22 KO revealed $\leq 5$ eosinophils/HPF, with the majority of HPF containing only $0-2$ eosinophils. Thus, while eosinophil influx may characterize oxazolone-induced colitis, they are not a prerequisite for disease and significant colitis can develop in the absence of eosinophils as shown by this assessment of CCL11/CCL22 KO mice.

\section{Ad.IL-5 Enhances Oxazolone-Induced Colitis}

Serum levels of IL-5 24 hours after injection of Ad.IL-5 were $488 \pm 55^{\star} \mathrm{pg} / \mathrm{ml}$ compared to controls at $139 \pm 21$ $\mathrm{pg} / \mathrm{ml}\left(n=4 ;{ }^{*}, P<0.05\right)$, confirming bioactivity of the adenovirus. Similarly, levels of IL-5 were significantly increased in sera from Ad.IL-5 or oxazolone+Ad.IL-5treated mice at the end of the experiment (Figure 5).

Analysis revealed no statistical differences in the colon of ethanol-treated control mice and mice receiving either Ad.IL-5 or Ad.delete only and this dose of nonreplicating adenovirus did not evoke an increase in blood polymorphonuclear (PMNs) immune cells: control $=29 \pm 5 \%$ versus Ad.IL5 $=27 \pm 5 \%$ of blood immune cells. In contrast, mice treated with Ad.IL$5+$ oxazolone or Ad.delete+oxazolone displayed significant increases in PMNs $(n=4)$, of $61 \pm 11 \%$ and
A
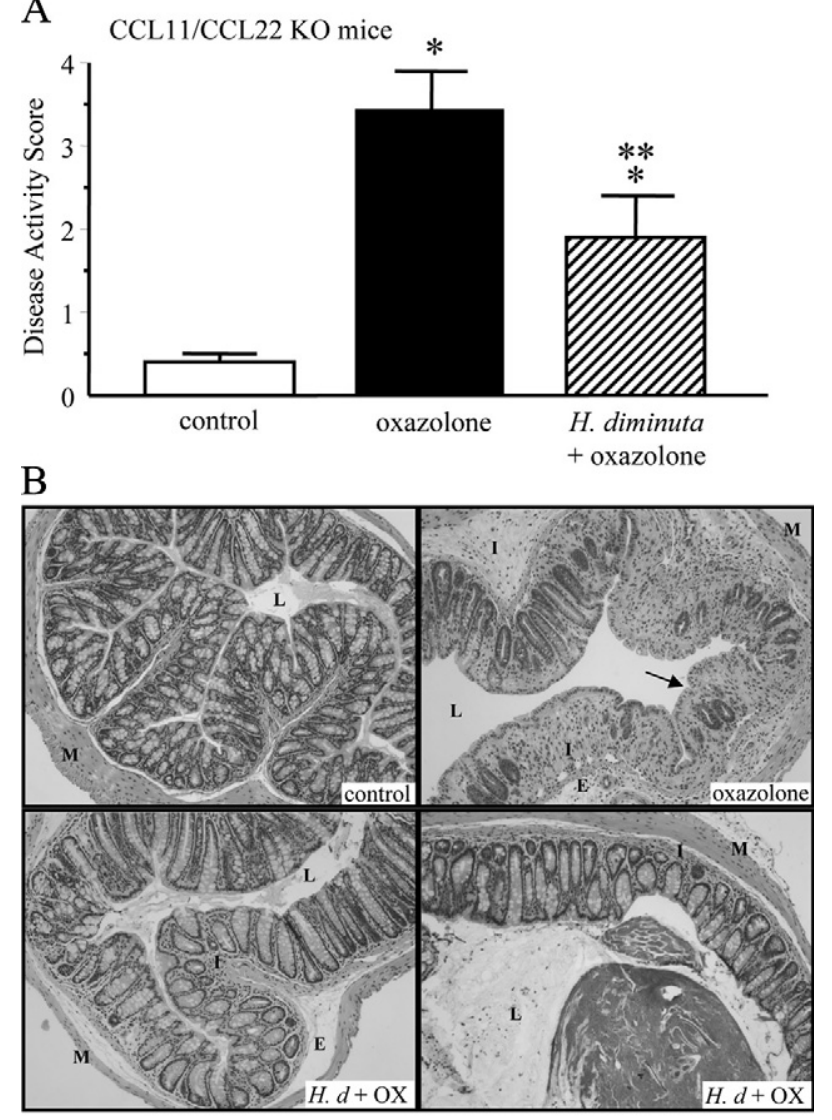

$\mathrm{C}$

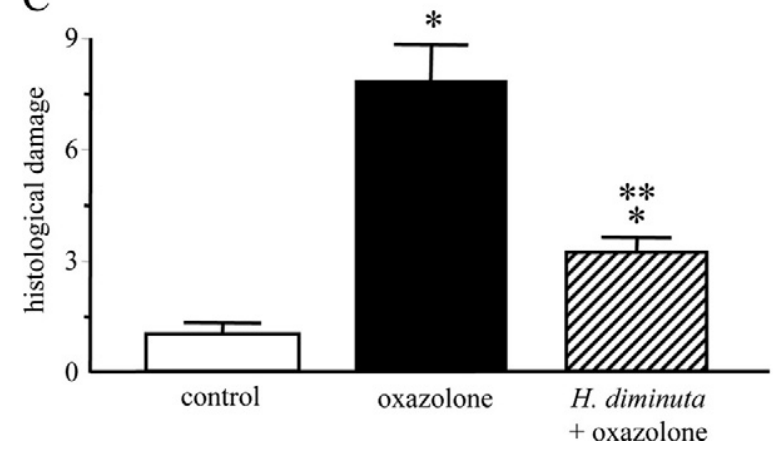

Figure 4. Infection with $H$. diminuta partially protects CCL11/CCL22 (eotaxin 1/2) KO mice from the colitis-induced instillation of oxazolone (OX; $3 \mathrm{mg}, 72$ hours before autopsy) as assessed by (A) disease activity (DAS) and (C) histological damage scores [mean \pm SEM; $n=6-7$ mice from two experiments; ${ }^{*} P<0.05$ compared to control and ${ }^{* *} P<0.05$ compared to control and oxazolone, respectively; five cysticercoids of $H$. diminuta $(H . d)$ given by oral gavage 8 days before oxazolone]. Panel $\mathbf{B}$ is representative images from H\&E sections of the colon (E, edema; I, inflammatory infiltrate; $\mathrm{L}$, lumen of colon; M, outer muscle layers; arrow indicates major architectural disruption; original magnification, $\times 200$; note dilation of the lumen in the second example of $H . d+$ OX-treated mice).

$58 \pm 9 \%$ of blood leukocyte, respectively. In addition, mice treated with Ad.IL-5 \pm oxazolone had increased numbers of eosinophils in the colon: control $=9 \pm 3$, Ad.IL-5 = $28 \pm 3^{\star}$, oxazolone $=19 \pm 4,{ }^{*}$ Ad.IL-5+oxazolone $=23 \pm 2^{*}$ and Ad.delete+oxazolone $=18 \pm$ $4^{*}$ eosinophils/HPF of view $\left(n=3-4 ;{ }^{*}, P<0.05\right.$ compared to control). There was no difference between the oxazolone- and Ad.IL-5+oxazolone-treated mice in terms of absolute eosinophil numbers, but this 


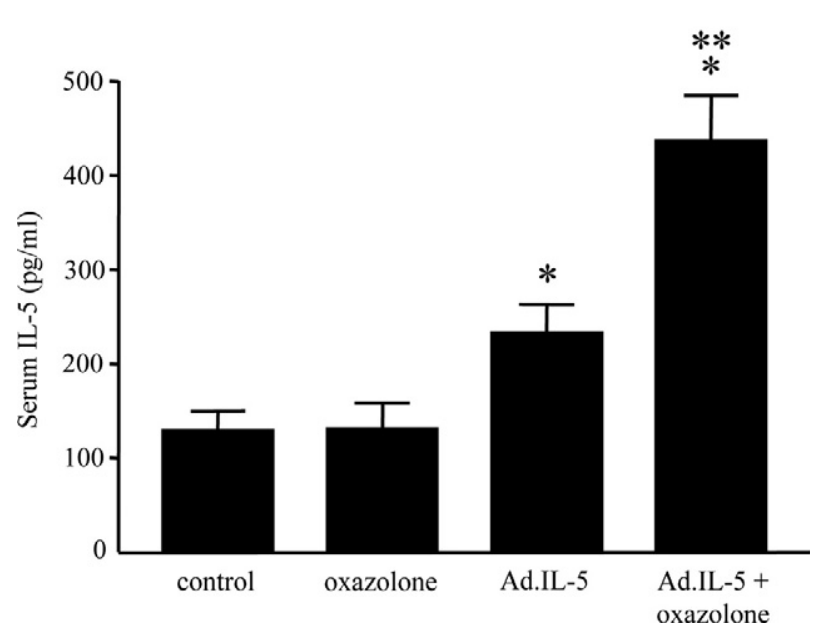

Figure 5. Bar graph showing serum levels of IL-5 four days after ip injection of Ad.IL-5 ( $10^{8} \mathrm{pfu}, \mathrm{ip}$.) and 3 days postoxazolone $(3 \mathrm{mg}$, ir) (mean \pm SEM; $n=4 ;{ }^{*} P<0.05$ compared to control and ${ }^{* *} P<0.05$ compared to Ad.IL-5, respectively).

gives no indication of the activation status of the recruited cells. These histological observations were supported by significant increases in EPO levels in colonic segments excised from oxazolone \pm adenovirus treated mice as compared to naïve mice or mice injected with Ad.IL-5 or Ad.delete only (data not shown).

Mice cotreated with oxazolone+Ad.delete had, on average, slightly more severe disease (likely reflecting a response to the small dose of virus); however, there were no statistical differences in the colitis in Ad.delete+ oxazolone compared to oxazolone-treated mice. In contrast, mice that received Ad.IL-5+oxazolone displayed a significant increase in the severity of the colitis (Figure 6, $\mathrm{A}-\mathrm{C}$ ): histological examination revealed greater derangement of colonic architecture, more inflammatory cell infiltrate, and more extensive epithelial erosion and ulceration (Figure 7). Colonic levels of MPO activity were quite variable between experiments, and were statistically significantly increased in tissues from oxazolone $(0.9 \pm 0.2$, * $n=18)$, oxazolone+Ad.IL-5 (1.8 $\left.\pm 0.4,{ }^{* \#} n=18\right)$ and oxazolone+Ad.delete $\left(0.7 \pm 0.2,{ }^{*} n=9\right)$ treated mice compared to those from control mice $(0.3 \pm 0.05 \mathrm{U} / \mathrm{mg}$ tissue, $n=18)\left({ }^{*}, P<0.05\right.$ compared to control; \#, $P<$ 0.05 compared to oxazolone and oxazolone+Ad.delete).

\section{LPS-Activated Eosinophils Decrease Epithelial Barrier Function}

A 48-hour exposure to eosinophils or LPS only had negligible effects on the barrier function of T84 epithelial cell monolayers. However, coculture with the HL-60 eosinophil cell line exposed to $100 \mathrm{ng} / \mathrm{ml}$ of E. coli LPS had a significant impact on epithelial permeability as shown by a drop in transepithelial resistance of $\sim 40 \%$ and a fourfold increase in the transepithelial flux of HRP (Figure 8, A and B).
A

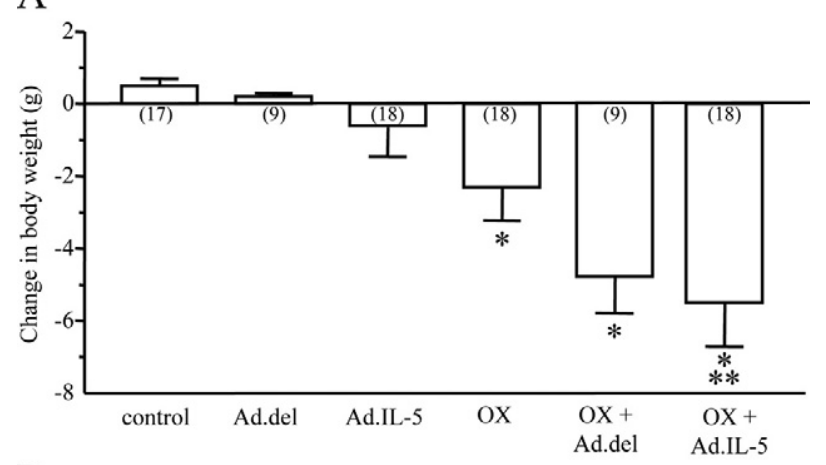

$\mathrm{B}$
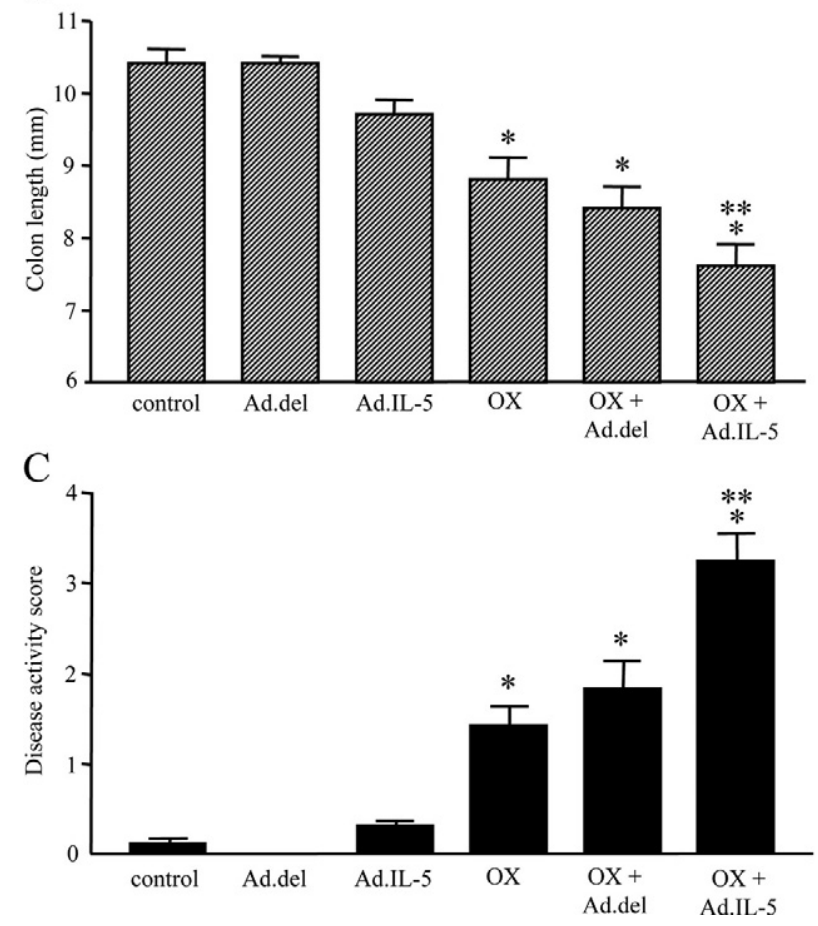

Figure 6. Bar graphs showing the exaggeration of colitis in Ad.IL-5 $\left[10^{8} \mathrm{pfu}\right.$ ip. 24 hours before oxazolone (OX)]+oxazolone ( $3 \mathrm{mg}$ ir.) treated mice as assessed by change in body weight $(\mathbf{A})$, colon length $(\mathbf{B})$, and disease activity scores $(\mathbf{C})$ [mean $\pm \mathrm{SEM}$; $\mathrm{n}$ values shown in parentheses in panel $\mathbf{A}$ (from 3 to 5 experiments); assessment conducted 72 hours after oxazolone; ${ }^{*} P<0.05$ compared to control and ${ }^{* *} P<0.05$ compared oxazolone, respectively].

\section{Potentially Antiinflammatory Effects of Infection with $\mathrm{H}$. diminuta Do Occur in the Oxazolone Model of Colitis}

Consistent with our earlier studies, ${ }^{21}$ ConA stimulation of spleen cell or lamina propria lymphocyte cultures from mice infected 11 days previously with $H$. diminuta \pm oxazolone (given at 8 days postinfection) produced more IL-10 than cells from control mice or those treated with oxazolone only (Figure 9).

\section{Discussion}

Proinflammatory roles have been shown for IL-5 and eosinophils in the context of inflammation in the airways. ${ }^{22}$ In comparison, the significance of increases in eosino- 


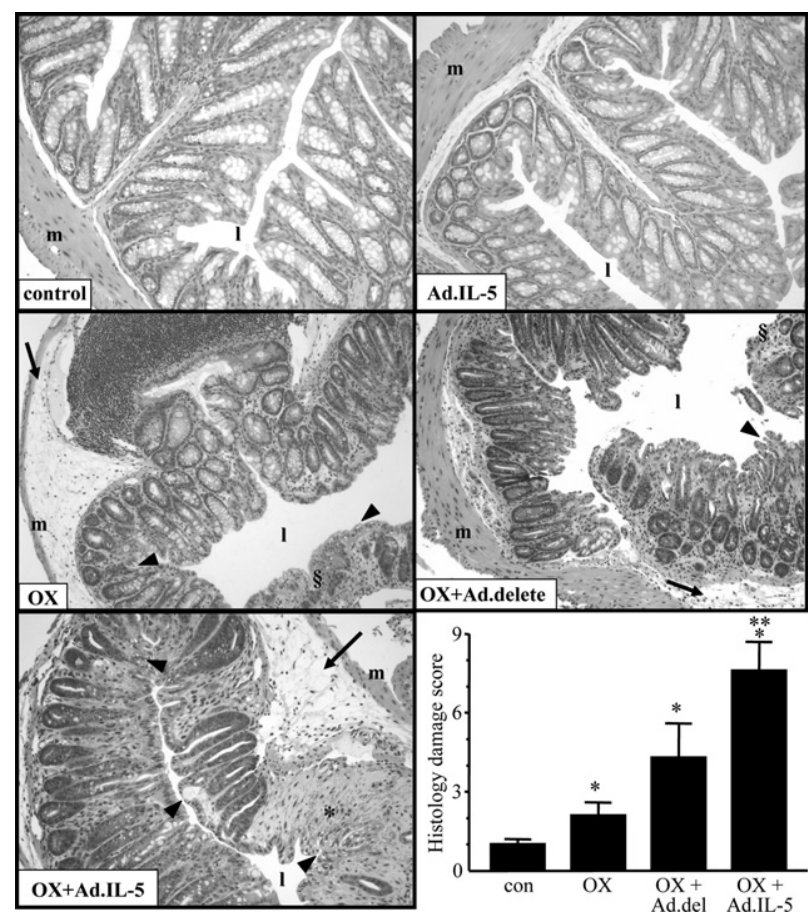

Figure 7. Representative images of H\&E sections of the colon from the various groups of mice with the resultant histological damage scores from control (con), oxazolone ( $3 \mathrm{mg}$ ir, +72 hours) and oxazolone+Ad.delete or Ad.IL-5 ( $10^{8}$ pfu, ip.)-treated mice (mean \pm SEM; $n=9-18$ from 3 to 5 experiments; ${ }^{*} P<0.05$ compared to control and ${ }^{* *} P<0.05$ compared to oxazolone, respectively; $\mathrm{m}$, muscle; 1 , lumen; arrowhead, friable epithelium; arrow, inflammatory infiltrate; asterisk, ulceration; original magnification, $\times 200)$.

phils in the blood or colon of patients with IBD, particularly those with ulcerative colitis, is unclear. ${ }^{23-26}$ The correlation of increased numbers of eosinophils in inflamed tissue and the ability of eosinophil-derived molecules (eg, major basic protein) to cause tissue damage has led to the supposition that these cells contribute to inflammation: a postulate supported by data from animal models of colitis. ${ }^{27-30}$ However, the release of TGF $\beta$ from eosinophils can promote tissue restitution. ${ }^{31}$ Indeed, recognition of multiple functional phenotypes within a given type of immune cell lineage ${ }^{32}$ raises the possibility that subgroups of eosinophils could exert anti-inflammatory effects.

Infection with helminth parasites can reduce the severity of concomitant disease in animal models. ${ }^{1,33}$ Such studies have much to offer in the assessment of pathophysiology and the identification of endogenous mechanisms to down-regulate inflammation. However, the possibility that infection with helminth parasites could exaggerate disease cannot be overlooked, as for example in Citrobacter rodentium-induced enteropathy ${ }^{34}$ and oxazolone-induced colitis. ${ }^{13}$ Given the commonality of i) increased IL-4 in ulcerative colitis and murine oxazolonecolitis, ii) increased eosinophils in oxazolone-induced colitis ${ }^{15}$ and some patients with ulcerative colitis, ${ }^{24}$ and iii) the mobilization of IL-5 and eosinophils after infection with helminth parasites, ${ }^{35}$ we hypothesized that IL-5 and eosinophils participated in the worsening of oxazoloneinduced colitis in $\mathrm{H}$. diminuta-infected mice. The subse-
A
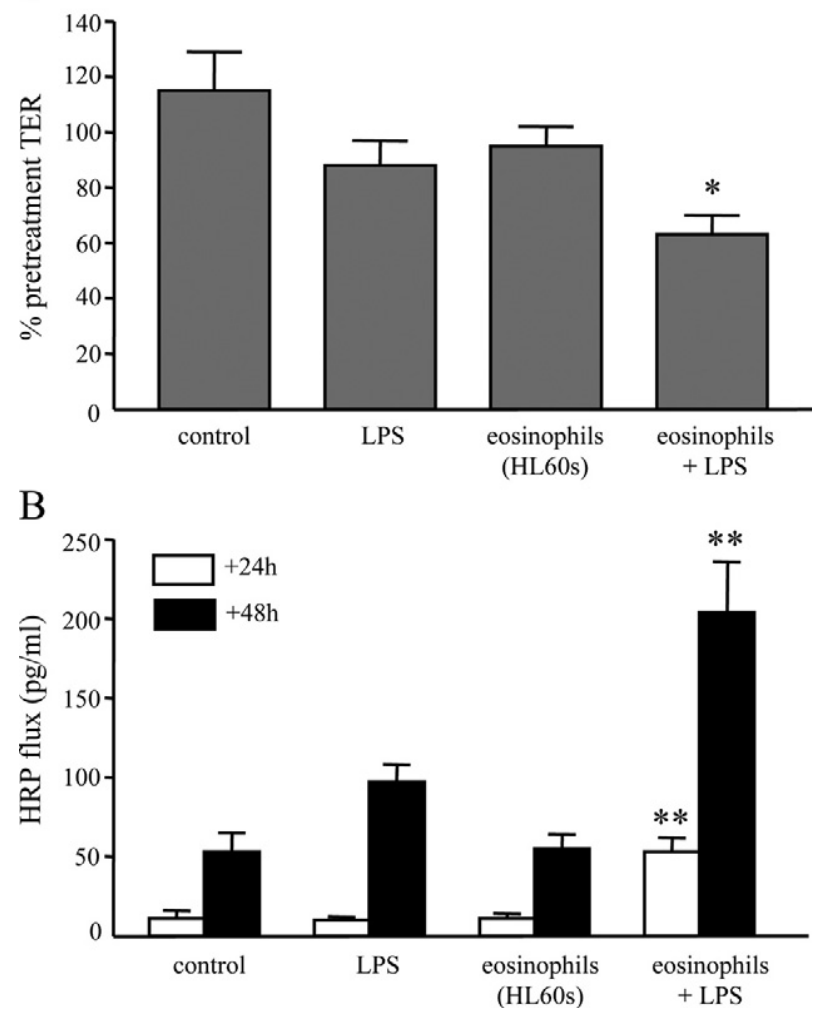

Figure 8. Coculture with HL-60 differentiated eosinophils $\left(1 \times 10^{5}\right)$ and LPS $(100 \mathrm{ng} / \mathrm{ml})$ results in increased permeability of monolayers of the human colon-derived T84 epithelial cell line as measured by (A) transepithelial electrical resistance (TER: a measure of the paracellular barrier to the passive flux of ions) and (B) the apical to basolateral flux of horse-radish peroxidase (HRP, a $44-\mathrm{kDa}$ protein) 48 hours later [mean $\pm \mathrm{SEM} ; n=6$ epithelial monolayers from two experiments; starting TER $=790-2460 \Omega / \mathrm{cm}^{2} ;{ }^{*} P<$ 0.05 compared to control (ie, T84 cells only); ${ }^{* *} P<0.05$ compared to other groups].

quent analyses support three conclusions: first, the exaggeration of oxazolone-induced colitis observed in $H$. diminuta-infected mice is inhibited by in vivo neutralization of IL-5; second, increased production of IL-5 worsens the outcome of oxazolone-induced colitis; and, third, despite a more severe disease in $\mathrm{H}$. diminuta+oxazolone

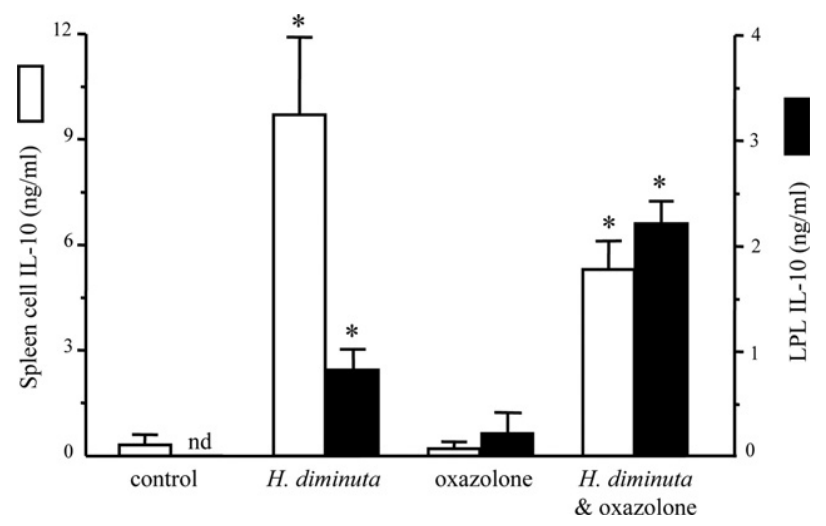

Figure 9. Bar graph showing IL-10 production from spleen cells and lamina propria lymphocytes (LPLs) 48 hours after ConA $(2 \mu \mathrm{g} / \mathrm{ml})$ stimulation (mean \pm SEM; $n=3$ from a representative experiment; ${ }^{*} P<0.05$ compared to control and oxazolone only; nd, not detected). 
treated mice, aspects of an antiinflammatory effect of $H$. diminuta still occur.

The beneficial effect of infection with $H$. diminuta in DNBS-induced colitis $3,36,37$ raises the question as to why infection with this parasite is so detrimental in oxazoloneinduced colitis. ${ }^{13}$ Increases in IL-4 that are superseded by increases in IL-13 production and a mild colonic eosinophilia are characteristic of oxazolone-induced colitis. ${ }^{14}$ We showed that the exaggerated disease in $\mathrm{H}$. diminuta + oxazolone-treated mice was accompanied by increases in IL-5 and CCL11 mRNA and enhanced eosinophilia in the colon. ${ }^{13}$ Here we extend these observations by showing that infection with $H$. diminuta ( \pm oxazolone) results in increased bone marrow production of eosinophils, a blood eosinophila, and that systemic and local levels of IL-5 can be increased via activation of spleen cells and LPLs. These data raise the possibility that the severe colitis in $\mathrm{H}$. diminuta+oxazolone-treated mice could be via production of IL-5 and subsequent eosinophil differentiation and activation.

In vivo neutralization of IL-5 (using an antibody strategy) inhibited the $H$. diminuta-induced exaggeration of oxazolone-colitis $(H$. diminuta was not observed in the small intestine of the anti-IL-5 AB-treated mice, indicating that key signal transducer and activator of transcription 6-driven events required for the expulsion of the worm ${ }^{38}$ were intact). Moreover, the amelioration of colitis in these animals was accompanied by reduced numbers of circulating and colonic eosinophils, supporting the postulate that $H$. diminuta exaggeration of oxazoloneinduced colitis is at least partially due to the recruitment of eosinophils to the gut. Lack of IL-5 attenuated the accumulation of eosinophils in the colon of dextran-sodium sulfate (DSS)-treated mice ${ }^{26,27}$; however, the degree of colitis was similar in wild-type and IL-5 KO mice, likely reflecting redundancy of proinflammatory events in DSS-colitis. This increase in eosinophils in DSS-induced colitis may explain, at least partially, the finding that infection with $H$. diminuta alleviated the ion transport abnormalities but not the histopathology in this model of colitis. ${ }^{39}$ However, colitis in oxazolone and oxazolone+ anti-IL-5 AB-treated mice were similar. Thus, while coIonic eosinophilia is characteristic of this model of colitis, these cells may play only a small role in the disease such that the normal variation between mice in their response to oxazolone is large enough to mask any role of eosinophils that could potentially be revealed by neutralization of IL-5.

Mice deficient in CCL11 develop less colitis than normal animals treated with DSS. ${ }^{27}$ Treatment of CCL11/ CCL22 KO with oxazolone resulted in an obvious colitis that was not appreciably different from that which develops in normal mice. However, and in contrast to normal BALB/c mice, infection with $H$. diminuta reduced the degree of colitis in $\mathrm{KO}$ mice. These findings are compatible with eosinophil participation in $H$. diminuta enhancement of oxazolone-induced colitis and suggest that any antiinflammatory effect (ie, the increase in IL-10 production) of infection with $\mathrm{H}$. diminuta is superseded by the eosinophil effect. This underscores the complexity of the inflammation in the gut, where the outcome will be dependent on the interplay between numerous immune, stromal and neuronal cells. ${ }^{40}$

Consistent with the inhibition of colitis in $H$. diminuta+oxazolone treated mice by anti-IL-5 AB, overexpression of IL-5 significantly increased the severity of oxazolone-induced colitis. The question remains as to precisely how IL-5/eosinophils enhance oxazolone-induced disease. In vitro coculture studies reveal that eosinophils can reduce the barrier properties of epithelial cell monolayers and that this is enhanced by the addition of the bacterial tri-peptide, fMet-Leu-Phe. ${ }^{18}$ Furthermore, major basic protein was found to increase murine colonic epithelial permeability and exaggerate colitis. ${ }^{29}$ Also, preliminary evidence suggests that eosinophil activation results in increases in epithelial permeability in biopsy specimens from patients with ulcerative colitis. ${ }^{41}$ Thus, the current study (Figure 8) adds to a small body amount of data suggesting that one mechanism by which eosinophils could enhance intestinal inflammation is by the induction of decreases in epithelial barrier function.

Having implicated IL-5, a cytokine considered indispensable for eosinophil differentiation, survival, and function, ${ }^{31}$ in the exaggeration of oxazolone-induced colitis, other mechanistic possibilities should not be overlooked. Thus, participation of i) IL-4 and IL-13 [cytokines mobilized in response to infection with helminth parasites and oxazolone (and possibly important in ulcerative colitis also)], ii) NK and NK T cells, ${ }^{14,15}$ and iii) TGF $\beta^{13,14}$ should be assessed in the $H$. diminuta+oxazolone model and any putative interaction with IL-5 or eosinophils defined.

Some patients with ulcerative colitis experienced benefit when given viable ova of the nematode, Trichuris suis, ${ }^{8}$ while allergic rhinitis was unaffected by infection with this helminth. ${ }^{42}$ If eosinophils are increased in ulcerative colitis, ${ }^{23}$ how can these clinical observations be reconciled with the data herein? Eosinophil levels were not documented in the clinical trial. ${ }^{8}$ Thus, the disease in this cohort of patients may not have had significant eosinophil involvement or $T$. suis may not have evoked a large eosinophilia in patients with a positive response to the helminth therapy. Also, it is important to emphasize that the essence of parasitism is host-specificity, and so the local and systemic responses to $H$. diminuta (a cestode) in mice need not be identical to those in humans in response to $T$. suis (a nematode): thus, host-parasite specific interactions could explain the disparity between the human and animal model investigations. In addition, oxazolone-induced colitis recapitulates neither the etiology of ulcerative colitis nor all of the nuances of the human condition. Nevertheless the analysis of the $H$. diminuta+oxazolone model indicates that an eosinophilic response could undermine the benefit of antiinflammatory events mobilized subsequent to infection with helminth parasites.

In summary, this study confirms that infection with the rat tapeworm, Hymenolepis diminuta, exaggerates disease in a TH2-biased murine model of acute colitis ${ }^{13}$ and that IL-5-and by inference eosinophils-participates in the enhanced inflammation. However, an anticolitic effect of infection with $\mathrm{H}$. diminuta was observed in CCL11/ CCL22 KO mice, highlighting that antiinflammatory or 
immunoregulatory events that accompany infection with helminth parasites could be exploited therapeutically. Finally, the impact of infection with a helminth parasite is contextual, depending on the health status of the host and the nature of any concomitant disease, and a consideration of these parameters could be paramount in the assessment of the potential use of a therapeutic helminth.

\section{Acknowledgment}

We thank Meaghan M. Hunter (formerly of McMaster University) for conducting pilot studies.

\section{References}

1. McKay DM: The therapeutic helminth? Trends Parasitol 2009, 25:109-114

2. Ince MN, Elliott DE, Setiawan T, Metwali A, Blum A, Chen HL, Urban JF, Flavell RA, Weinstock JV: Role of T cell TGF- $\beta$ signaling in intestinal cytokine responses and helminthic immune modulation. Eur J Immunol 2009, 39:1870-1878

3. Hunter MM, Wang A, Hirota CL, McKay DM: Neutralizing anti-IL-10 antibody blocks the protective effect of tapeworm infection in a murine model of chemically-induced colitis. J Immunol 2005, 174:73687375

4. Elliott DE, Metwali A, Leung J, Setiawan T, Blum AM, Ince MN, Bazzone LE, Stadecker MJ, Urban JF Jr, Weinstock JV: Colonization with Heligmosomoides polygyrus suppresses mucosal IL-17 production. J Immunol 2008, 181:2414-2419

5. Khan WI, Blennerhassett PA, Varghese AK, Chowdhury SK, Omsted $\mathrm{P}$, Deng $\mathrm{Y}$, Collins SM: Intestinal nematode infection ameliorates experimental colitis in mice. Infect Immunity 2002, 71:5931-5937

6. Wilson MS, Taylor MD, Balic A, Finney CA, Lamb JR, Maizels RM: Suppression of allergic airway inflammation by helminth-induced regulatory T cells. J Exp Med 2005, 202:1199-1212

7. Smith $\mathrm{P}$, Mangan NE, Walsh CM, Fallon RE, McKenzie AN, van Nooijen RN, Fallon PG: Infection with a helminth parasite prevents experimental colitis via a macrophage-mediated mechanism. J Immunol 2007, 178:4557-4566

8. Summers RW, Elliott DE, Urban JF (Jr), Thompson RA, Weinstock JV: Trichuris suis therapy for active ulcerative colitis: a randomized controlled trial. Gastroenterology 2005, 128:825-832

9. Mortimer K, Brown A, Feary J, Jagger C, Lewis S, Antoniak M, Pritchard D, Britton J: Dose-ranging study for trials of therapeutic infection with Necator americanus in humans. Am J Trop Med Hyg 2006, 75:914-920

10. Hunter MM, Wang A, Parhar KS, Johnston MJ, van Nooijen R, Beck $\mathrm{PL}$, McKay DM. In vitro-derived alternatively activated macrophages reduce colonic inflammation in mice. Gastroenterology 2010, 138: 1395-1405

11. Hotez PJ, Brindley PJ, Bethony JM, King CH, Pearce EJ, Jacobson J: Helminth infections: the great neglected tropical diseases. J Clin Invest 2008, 118:1311-1321

12. van Kruiningen $H J$, West $A B$ : latrogenic Trichuris suis infection. Arch Pathol Lab Med 2007, 131:180-181

13. Hunter MM, Wang A, McKay DM: Helminth infection enhances disease in a murine TH2 model of colitis. Gastroenterology 2007, 132:1320-1330

14. Boirivant M, Fuss I, Chu A, Strober W: Oxazolone colitis: a murine model of $\mathrm{T}$ helper cell type 2 colitis treatable with antibodies to interleukin 4. J Exp Med 1998, 188:1929-1939

15. Heller F, Fuss IJ, Nieuwenhuis EE, Blumberg RS, Strober W: Oxazolone colitis, a Th2 colitis model resembling ulcerative colitis, is mediated by IL-13 producing NK-T cells. Immunity 2002, 17: 629-638

16. Rothenberg ME, MacLean JA, Pearlman E, Luster AD, Leder P: Targeted disruption of the chemokine eotaxin partially reduces antigen-induced tissue eosinophilia. J Exp Med 1997, 185:785790
17. Bramson JL, Graham FL, Gauldie J: The use of adenoviral vectors for gene therapy and gene transfer in vivo. Curr Opin Biotech 1995, 6:590-595

18. Michail S, Abernathy F: A new model for studying eosinophil migration across cultured intestinal epithelial monolayers. J Pediatr Gastroenterol Nutr 2004, 39:56-63

19. Reardon C, Wang A, McKay DM: Transient local depletion of Foxp3 ${ }^{+}$ regulatory $T$ cells during recovery from colitis via Fas/Fas ligandinduced death. J Immunol 2008, 180:8316-8326

20. McKay DM, Croitoru K, Perdue MH: T cell monocyte interactions regulate epithelial physiology in a co-culture model of inflammation. Am J Physiol Cell Physiol 1996, 270:C418-C428

21. Lampinen M, Carlson M, Sangfelt P, Taha Y, Thorn M, Loof L, Raab Y Venge P: IL- 5 and TNF- $\alpha$ participate in recruitment of eosinophils to intestinal mucosa in ulcerative colitis. Dig Dis Sci 2001, 46:20042009

22. O'Byrne PM, Inman MD, Parameswaran K: The trials and tribulations of IL-5, eosinophils, and allergic asthma. J Allergy Clin Immunol 2001, 108:503-508

23. Carvalho AT, Elia CC, de Souza HS, Elias PR, Pontes EL, Lukashok HP, de Freitas FC, Lapa e Silva JR: Immunohistochemical study of intestinal eosinophils in inflammatory bowel disease. J Clin Gastroenterol 2003, 36:120-125

24. Ahrens R, Waddell A, Seidu L, Blanchard C, Carey R, Forbes E, Lampinen M, Wilson T, Cohen E, Stringer K, Ballard E, Munitz A, Xu H, Lee N, Lee JJ, Rothenberg ME, Denson L, Hogan SP: Intestinal macrophage/epithelial cell-derived CCL11/eotaxin-1 mediates eosinophil recruitment and function in pediatric ulcerative colitis. J Immunol 2008, 181:7390-7399

25. Lampinen M, Backman M, Winqvist O, Rorsman F, Ronnblom A Sangfelt $P$, Carlson M: Different regulation of eosinophil activity in Crohn's disease compared with ulcerative colitis. J Leukoc Biol 2008, 84:1392-1399

26. Lampinen M, Carlson M, Hakansson LD, Venge P: Cytokine-regulated accumulation of eosinophils in inflammatory disease. Allergy 2004, 59:793-805

27. Forbes E, Murase T, Yang M, Matthaei KI, Lee JJ, Lee NA, Foster PS, Hogan SP: Immunopathogenesis of experimental ulcerative colitis is mediated by eosinophil peroxidase. J Immunol 2004, 172:5664-5675

28. Takedatsu H, Mitsuyama K, Matsumoto S, Handa K, Suzuki A, Takedatsu H, Funabashi H, Okabe Y, Hara T, Toyonaga A, Sata M: Interleukin-5 participates in the pathogenesis of ileitis in SAMP1/Yit mice. Eur J Immunol 2004, 34:1561-1569

29. Furuta GT, Nieuwenhuis EE, Karhausen J, Gleich G, Blumberg RS, Lee JJ, Ackerman SJ: Eosinophils alter colonic epithelial barrier function: role for major basic protein. Am J Physiol Gastrointest Liver Physiol 2005, 289:G890-G897

30. Stevceva L, Pavli P, Husband A, Matthaei KI, Young IG, Doe WF Eosinophilia is attenuated in experimental colitis induced in IL-5 deficient mice. Genes Immun 2000, 1:213-218

31. Hogan SP: Recent advances in eosinophil biology. Int Arch Allergy Immunol 2007, 143(Suppl 1):3-14

32. Reyes JL, Terrazas LI: The divergent roles of alternatively activated macrophages in helminthic infections. Parasite Immunol 2007, 29:609-619

33. Elliott DE, Summers RW, Weinstock JV: Helminths as governors of immune-mediated inflammation. Int J Parasitol 2007, 37:457-464

34. Chen CC, Louie S, McCormick B, Walker WA, Shi HN: Concurrent infection with an intestinal helminth parasite impairs host resistance to enteric Citrobacter rodentium and enhances Citrobacter-induced colitis in mice. Infect Immun 2005, 73:5468-5481

35. Else KJ, Finkelman FD: Intestinal nematode parasites, cytokines and effector mechanisms. Int J Parasitol 1998, 28:1145-1158

36. Persaud R, Wang A, Reardon C, McKay DM: Characterization of the immuno-regulatory response to the tapeworm Hymenolepis diminuta in the non-permissive mouse host. Int J Parasitol 2007, 37:393-403

37. Melon A, Wang A, Phan V, McKay DM: Infection with Hymenolepis diminuta is more effective than daily corticosteroids in blocking chemically induced colitis in mice. J Biomed Biotechnol 2010, 2010:384523

38. McKay DM, Khan WI: STAT-6 is an absolute requirement for murine rejection of Hymenolepis diminuta. J Parasitol 2003, 89:188-189 
39. Reardon C, Sanchez A, Hogaboam CM, McKay DM: Tapeworm infection reduces the ion transport abnormalities induced by dextran sulphate sodium (DSS) colitis. Infect Immunity 2001, 69:4417-4423

40. Perdue MH, McKay DM: Integrative immunophysiology in the intestinal mucosa. Am J Physiol Gastrointest Liver Physiol 1994, 267: G151-G165

41. Wallon C, Ericson AC, Yang P-C, McKay DM, Sherman PM, Perdue $\mathrm{MH}$, Soderholm JD: Increased macromolecular permeability in non-inflamed colon of ulcerative colitis involves muscarinic receptor signaling via subepithelial eosinophils. Gastroenterology 2008, 134:A397

42. Bager P, Arnved J, Ronborg S, Wohlfahrt J, Poulsen LK, Westergaard T, Petersen HW, Kristensen B, Thamsborg S, Roepstorff A, Kapel C, Melbye M: Trichuris suis ova therapy for allergic rhinitis: a randomized, double-blind, placebo-controlled clinical trial. J Allergy Clin Immunol 2010, 125:123-130 